\title{
Pengaruh Daya Tarik Iklan, Harga, Word of Mouth (WoM) terhadap Minat Beli Produk Koi Café Palembang
}

\author{
Arlincia Chandra Yudha1, Rezi Erdiansyah ${ }^{2 *}$ \\ ${ }^{1}$ Fakultas Ilmu Komunikasi, Universitas Tarumanagara, Jakarta \\ Email: arlinciacy@gmail.com \\ ${ }^{2}$ Fakultas Ilmu Komunikasi, Universitas Tarumanagara, Jakarta* \\ Email: rezie@fikom.untar.ac.id
}

Masuk tanggal : 15-12-2021 revisi tanggal : 06-01-2022, diterima untuk diterbitkan tanggal : 16-01-2022

\begin{abstract}
This research was conducted to find out the influence of the attractiveness of advertising, Price, Word of Mouth, on the interest in buying Koi Cafe products. The survey was conducted by sharing Google form links to all consumers who had visited and transacted at Koi Café. As many as 100 respondents from the sample. From the results of the study obtained that the coefficient of determination value showed results of 0.88 or $88.6 \%$ which means the variation in buying interest of Koi Cafe products can be explained by variations in independent variables (advertising attractiveness, price, word of mouth) and the remaining 0.114 or $11.4 \%$ is another influence outside the research conducted. this can conclude that the attractiveness of advertising, price, word of mouth, affects the buying interest of Koi Café products.
\end{abstract}

Keywords: advertising attractiveness, buying interest, Koi Café, price, word of mouth

\begin{abstract}
Abstrak
Peneliti melakukan penelitian ini untuk mengetahui apakah daya tarik iklan, harga, Word of Mouth, memiliki pengaruh terhadap minat beli produk Koi Cafe. Survey dilakukan dengan membagikan link Google form kepada seluruh konsumen yang pernah mengunjungi dan bertransaksi di Koi Café sebanyak 100 responden dari sampel yang digunakan peneliti. Dari hasil penelitian yang diperoleh bahwa nilai Koefisien Determinasi menunjukkan hasil sebesar 0,88 atau $88,6 \%$ yang berarti variasi minat beli produk Koi Cafe bisa dijelaskan oleh variasi variabel independent (daya tarik iklan, harga, word of mouth) dan sisanya sebesar 0,114 atau 11,4\% merupakan pengaruh lain di luar penelitian yang dilakukan. Dengan ini peneliti dapat menyimpulkan bahwa daya tarik iklan, harga, word of mouth, memiliki pengaruh terhadap minat beli produk Koi Café.
\end{abstract}

Kata Kunci: daya tarik iklan, harga, Koi Café, minat beli, word of mouth

\section{Pendahuluan}

Bisnis pada era sekarang perkembangannya sangatlah pesat yang mempunyai dampak terhadap manusia. Dengan perkembangan teknologi yang kian pesat, banyak persaingan usaha yang dilakukan pengusaha setiap perusahaan untuk menjadi yang terbaik agar bisa dikenal masyarakat dan bersaing dipasar. Sekarang, perusahaan banyak melakukan perkembangan dengan cara salah satunya adalah dengan media sosial, untuk lebih dikenal oleh masyarakat dan bisa membuat pertumbuhan bisnis meningkat salah satunya adalah iklan di media sosial yang bisa menarik pelanggan dan juga memberikan informasi harga dari suatu produk tersebut. Dengan seperti itu penyebaran menjadi efisien, tidak memakan waktu. 
Dengan membagikan pengalaman para konsumen kepada teman atau keluarga terdekat, merupakan kegiatan pemasaran yang sangat efektif. Dengan ini, rumusan masalah pada penelitian ini adalah "bagaimana pengaruh daya tairk iklan, harga, word of mouth terhadap minat beli produk Koi Cafe'". Dan untuk tujuan penelitian ini dilakukan adalah: 1) Untuk mengetahui pengaruh daya tarik iklan terhadap minat beli produk Koi Café. 2) Untuk mengetahui pengaruh harga terhadap minat beli produk Koi Café. 3) Untuk mengetahui pengaruh word of mouth terhadap minat beli produk Koi Café. 4) Untuk mengetahui pengaruh simultan daya tarik iklan, harga, word of mouth terhadap minat beli produk Koi Café.

Menurut Philip Kotler (dalam Latief, Rusman dan Yusiatie Utud, 2017) menjelaskan bahwa, iklan sebagai media promosi yang dilakukan oleh suatu perusahaan. Sedangkan daya tarik iklan merupakan pengaruh dari sebuah iklan yang telah ditampilkan yang bertujuan menarik perhatian masyarakat dan membuat masyarakat tersebut terpengaruhi oleh iklan tersebut (Gunawan, F. A. dan Dharmayanti 2014). Menurut Suyanto (dalam Hartono, A. F., 2016) daya tarik iklan merupakan tahap awal saat melakukan kegiatan promosi, oleh karena itu daya tarik iklan merupakan suatu hal yang sangat penting agar mempunyai dampak kepada masyarakat.

Menurut Kotler dan Amstrong (dalam Tri Widodo, 2015) suatu barang atau produk dapat disebut sebagai uang, karena barang tersebut hasil dari pertukaran yang dilakukan oleh konsumen untuk menggunakan barang tersebut. Menurut Stanton (1996) dalam Agatha, M., mayoritas konsumen memiliki persepsi terhadap harga, yang mana tingginya harga maka produk tersebut memiliki kualitas yang sama dengan harga tersebut. Persitiwa tersebut terjadi karena tidak ada jalan lain untuk melihat apakah barang tersebut berkualitas atau tidak, selain melihat dari segi harga.

Menurut Kotler dan Keller (2009) menjelaskan bahwa komunikasi lisan, tertulis, dan elektronik terhadap hubungan yang terjadi pada masyarakat seperti pengalaman membeli suatu produk. Poerwanto dan Zakaria (2014) menjelaskan WOM adalah jenis promosi yang dilakukan konsumen kepada konsumen, dan untuk konsumen. WOM merupakan suatu komunikasi atau peristiwa yang bisa digunakan sebagai tolok ukur konsumen karena berawal dari konsumen yang pernah melakukan transaksi, mengonsumsi, atau menggunakan produk tersebut, dan memperoleh kepuasan yang kemudian merekomendasikan pengalaman menggunakan produk tersebut kepada orang lain.

Menurut Schiffman dan Kanuk (dalam Veronika, 2016) dapat dikatakan bahwa konsumen memiliki sikap tersendiri mereka dengan produk yang mereka inginkan, dan menunjukkannya dengan membeli atau membayar produk tersebut. Menurut Setiadi (dalam Adiba, 2016) pembentukan sikap konsumen terjadi karena sikap konsumen itu sendiri terhadap produk, dengan kepercayaan dan evaluasi tersebut muncullah minat untuk membeli produk tersebut.

\section{Metode Penelitian}

Penelitian yang dilakukan adalah penelitian berjenis pendekatan kuantitatif. Dalam pengumpulan datanya menggunakan populasi dan sampel. Pengambilan sampel dilakukan menggunakan rumus lemeshow karena jumlah yang tidak pasti. Penelitian ini menggunakan empat variabel yaitu daya tarik iklan yang mempunyai sembilan pernyataan, variabel harga mempunyai enam pernyataan, variabel word of mouth mempunyai sembilan pernyataan, dan minat beli mempunyai 12 pernyataan. 
Arlincia Chandra Yudha, Rezi Erdiansyah: Pengaruh Daya Tarik Iklan, Harga, Word of Mouth (WoM) terhadap Minat Beli Produk Koi Café Palembang

Semua pertanyaan tersebut dibagikan melalui survey yang dilakukan dengan membagikan link google form kepada seluruh responden yang telah berkunjung dan melakukan transaksi di Koi Café.

\section{Hasil Temuan dan Diskusi}

Peneliti menyebarkan kuesioner kepada 100 responden yang telah berkunjung dan melakukan transaksi di Koi Café. Jumlah responden perempuan adalah sebanyak 56 perempuan, dan 44 orang adalah laki-laki. Umur responden dalam penelitian ini yaitu sebanyak 27 orang (20-25 tahun), 23 orang (32-37 tahun), 18 orang (26-31 tahun), 17 orang (<19 tahun), lalu sebanyak 15 orang ( $>37$ tahun). Pendidikan terakhir responden adalah sebanyak 41 orang (SMA), sebanyak 29 orang (S1), sebanyak 16 orang (Diploma), sebanyak 8 orang (S2/S3), dan sebanyak 6 orang (lainnya). Pekerjaan responden adalah sebanyak 24 orang (P.Swasta), sebanyak 22 (mahasiswa), sebanyak 21 orang (P.Negeri), sebanyak 19 orang (wiraswasta), dan sebanyak 14 orang (lainnya). Jumlah kunjungan responden ke Koi Café dalam penelitian ini sebanyak 26 orang (1-2kali), sebanyak 26 (3-4kali), sebanyak 25 orang (> 6kali), dan sebanyak 23 orang (5-6kali). Jumlah melakukan transaksi adalah sebanyak 26 orang (1-2kali), sebanyak 26 orang (3-4kali), sebanyak 25 orang (> 6kali), dan sebanyak 23 orang (5-6kali). Berikut hasil penelitian data menggunakan SPSS:

Tabel 1. Hasil Uji Validitas Variabel X1

\begin{tabular}{lll}
\hline Item & Koefisien Validitas & Keterangan \\
\hline Pernyataan 1 & 0,602 & Valid \\
\hline Pernyataan 2 & 0,738 & Valid \\
\hline Pernyataan 3 & 0,693 & Valid \\
\hline Pernyataan 4 & 0,498 & Valid \\
\hline Pernyataan 5 & 0,663 & Valid \\
\hline Pernyataan 6 & 0,715 & Valid \\
\hline Pernyataan 7 & 0,751 & Valid \\
\hline Pernyataan 8 & 0,813 & Valid \\
\hline Pernyataan 9 & 0,680 & Valid \\
\hline
\end{tabular}

Sumber: Hasil Olah Data Peneliti

Uji Validitas variabel X1 diatas, bahwa dinyatakan valid karena nilai dari koefisien validitas dari setiap pernyataan berada di atas nilai standar validitas

Tabel 2. Hasil Uji Validitas Variabel X2

\begin{tabular}{lll}
\hline Item & Koefisien Validitas & Keterangan \\
\hline Pernyataan 1 & 0,789 & Valid \\
\hline Pernyataan 2 & 0,767 & Valid \\
\hline Pernyataan 3 & 0,758 & Valid \\
\hline Pernyataan 4 & 0,819 & Valid \\
\hline Pernyataan 5 & 0,600 & Valid \\
\hline Pernyataan 6 & 0,476 & Valid \\
\hline
\end{tabular}

Sumber: Hasil Olah Data Peneliti

Uji Validitas variabel X2 diatas, bahwa dinyatakan valid karena nilai dari koefisien validitas dari setiap pernyataan berada di atas nilai standar validitas 
Tabel 3. Hasil Uji Validitas Variabel X3 (Word of mouth)

\begin{tabular}{lll}
\hline Item & Koefisien Validitas & Keterangan \\
\hline Pernyataan 1 & 0,463 & Valid \\
\hline Pernyataan 2 & 0,713 & Valid \\
\hline Pernyataan 3 & 0,766 & Valid \\
\hline Pernyataan 4 & 0,649 & Valid \\
\hline Pernyataan 5 & 0,510 & Valid \\
\hline Pernyataan 6 & 0,485 & Valid \\
\hline Pernyataan 7 & 0,709 & Valid \\
\hline Pernyataan 8 & 0,724 & Valid \\
\hline Pernyataan 9 & 0,539 & Valid \\
\hline
\end{tabular}

Sumber: Hasil Olah Data Peneliti

Uji Validitas variabel X3 diatas, bahwa dinyatakan valid karena nilai dari koefisien validitas dari setiap pernyataan berada di atas nilai standar validitas

Tabel 4. Hasil Uji Validitas Variabel Y (Minat Beli)

\begin{tabular}{lll}
\hline Pernyataan 1 & 0,644 & Valid \\
\hline Pernyataan 2 & 0,667 & Valid \\
\hline Pernyataan 3 & 0,679 & Valid \\
\hline Pernyataan 4 & 0,636 & Valid \\
\hline Pernyataan 5 & 0,648 & Valid \\
\hline Pernyataan 6 & 0,496 & Valid \\
\hline Pernyataan 7 & 0,503 & Valid \\
\hline Pernyataan 8 & 0,703 & Valid \\
\hline Pernyataan 9 & 0,692 & Valid \\
\hline Pernyataan 10 & 0,659 & Valid \\
\hline Pernyataan 11 & 0,625 & Valid \\
\hline Pernyataan 12 & 0,402 & Valid \\
\hline
\end{tabular}

Sumber: Hasil Olah Data Peneliti

Uji Validitas variabel Y diatas, bahwa dinyatakan valid karena nilai dari koefisien validitas dari setiap pernyataan berada di atas nilai standar validitas

Tabel 5. Hasil Uji Reliabilitas

\begin{tabular}{lll}
\hline Uji Reliabilitas X1 & 0,852 & Reliabel \\
\hline Uji Reliabilitas X2 & 0,788 & Reliabel \\
\hline Uji Reliabilitas X3 & 0,775 & Reliabel \\
\hline Uji Reliabilitas Y & 0,845 & Reliabel
\end{tabular}

Sumber: Hasil Olah Data Peneliti

Uji Reliabilitas setiap variabel di atas, dinyatakan reliabel karena nilai dari setiap variabel lebih besar dari nilai rata-rata Cronbach's Alpha yaitu 0,6 dan dapat dinyatakan reliabel.

Tabel 5. Hasil Uji Koefisien Determinasi

\section{Model Summary}

\begin{tabular}{|c|c|c|c|c|}
\hline \multicolumn{5}{|c|}{ Model Summary } \\
\hline Model & $\mathrm{R}$ & R Square & Adjusted R Square & Std. Error of the Estimate \\
\hline 1 & $.943^{\mathrm{a}}$ & 0.889 & 0.886 & 2.07142 \\
\hline
\end{tabular}

Sumber: Hasil Olah Data Peneliti 
Uji Koefisien Determinasi diatas, bahwa $R$ Square adalah 0,889 atau 88,9\%. Lalu untuk Adjusted $R$ Square adalah 0,886 atau 88, persen. Dapat disimpulkan bahwa minat beli produk Koi Café bisa dijelaskan variabel daya tarik iklan, harga, word of mouth dan 0,114 atau 11,4\% merupakan faktor luar yang peneliti tidak lakukan atau sertakan.

Tabel 6. Hasil Uji Regresi Berganda

\section{Coefficients $^{\mathbf{a}}$}

\begin{tabular}{|c|c|c|c|c|c|c|}
\hline \multirow{2}{*}{\multicolumn{2}{|c|}{ Model }} & \multicolumn{2}{|c|}{$\begin{array}{l}\text { Unstandardized } \\
\text { Coefficients }\end{array}$} & \multirow{2}{*}{$\begin{array}{l}\text { Standardized } \\
\text { Coefficients } \\
\text { Beta }\end{array}$} & \multirow[b]{2}{*}{$\mathrm{t}$} & \multirow[b]{2}{*}{ Sig. } \\
\hline & & $\mathrm{B}$ & Std. Error & & & \\
\hline \multirow[t]{4}{*}{1} & (Constant) & 1.763 & 1.650 & & 1.069 & 0.288 \\
\hline & $\mathrm{x} 1$ & 0.886 & 0.072 & 0.747 & 12.360 & 0.000 \\
\hline & $\mathrm{x} 2$ & 0.222 & 0.125 & 0.108 & 1.778 & 0.079 \\
\hline & $\mathrm{x} 3$ & 0.203 & 0.118 & 0.134 & 1.722 & 0.088 \\
\hline
\end{tabular}

a. Dependent Variable: $y$

Sumber: Hasil Olah Data Peneliti

Koefisien regresi pada variabel X1, X2, X3 akan mengalami kenaikan atau penurunan sebesar dari nilai koefisien regresi pada setiap variabel. Maka, Y (variabel minat beli) akan mengalami kenaikan ataupun penuruan sebesar nilai koefisien regresi pada variabel independen.

Tabel 7. Hasil Uji T

Coefficients $^{\mathbf{a}}$

\begin{tabular}{|c|c|c|c|c|c|}
\hline \multirow[t]{2}{*}{ Model } & \multicolumn{2}{|c|}{$\begin{array}{l}\text { Unstandardized } \\
\text { Coefficients }\end{array}$} & \multirow{2}{*}{$\begin{array}{l}\text { Standardized } \\
\text { Coefficients } \\
\text { Beta }\end{array}$} & \multirow[t]{2}{*}{$\mathrm{t}$} & \multirow[t]{2}{*}{ Sig. } \\
\hline & $\mathrm{B}$ & Std. Error & & & \\
\hline $1 \quad$ (Constant) & 6.199 & 1.311 & & 4.728 & 0.000 \\
\hline $\mathrm{x} 1$ & 1.107 & 0.043 & 0.933 & 25.588 & 0.000 \\
\hline
\end{tabular}

a. Dependent Variable: $y$

\section{Coefficients $^{\mathrm{a}}$}

\begin{tabular}{|c|c|c|c|c|c|c|}
\hline \multirow{2}{*}{\multicolumn{2}{|c|}{ Model }} & \multicolumn{2}{|c|}{$\begin{array}{l}\text { Unstandardized } \\
\text { Coefficients }\end{array}$} & \multirow{2}{*}{$\begin{array}{l}\text { Standardized } \\
\text { Coefficients } \\
\text { Beta }\end{array}$} & \multirow[b]{2}{*}{$\mathrm{t}$} & \multirow[b]{2}{*}{ Sig. } \\
\hline & & $\mathrm{B}$ & Std. Error & & & \\
\hline \multirow[t]{2}{*}{1} & (Constant) & 7.296 & 2.993 & & 2.438 & 0.017 \\
\hline & $\mathrm{x} 2$ & 1.511 & 0.140 & 0.737 & 10.784 & 0.000 \\
\hline
\end{tabular}

a. Dependent Variable: y

\section{Coefficients $^{\mathbf{a}}$}

\begin{tabular}{llllll}
\hline & \multicolumn{2}{l}{$\begin{array}{l}\text { Unstandardized } \\
\text { Coefficients }\end{array}$} & \multicolumn{2}{l}{$\begin{array}{l}\text { Standardized } \\
\text { Coefficients }\end{array}$} & \\
\cline { 2 - 4 } Model & B & Std. Error & Beta & t & Sig. \\
\hline $1 \quad$ (Constant) & -0.384 & 2.594 & & -0.148 & 0.883 \\
\hline
\end{tabular}




\begin{tabular}{cccccc}
\hline $\mathrm{x} 3$ & 1.270 & 0.082 & 0.841 & 15.412 & 0.000 \\
\hline a. Dependent Variable: $\mathrm{y}$ & & & &
\end{tabular}

\section{Sumber: Hasil Olah Data Peneliti}

Uji $\mathrm{T}$ tabel di atas menjelaskan setiap variabel secara parsial menyatakan adanya pengaruh terhadap variabel $\mathrm{Y}$, yaitu nilai uji $\mathrm{t}$ dari setiap variabel dinyatakan $>$ dari t tabel 1,984 dan nilai signifikan sebesar 0,000 < 0,05. Sehingga peneliti menyimpulkan daya tarik iklan, harga, word of mouth mempunyai pengaruh signifikan terhadap minat beli produk Koi Café.

Tabel 8. Hasil Uji F

\begin{tabular}{|c|c|c|c|c|c|c|}
\hline & $\mathrm{OVA}^{\mathrm{a}}$ & & & & & \\
\hline & del & $\begin{array}{l}\text { Sum of } \\
\text { Squares }\end{array}$ & df & $\begin{array}{l}\text { Mean } \\
\text { Square }\end{array}$ & $\mathrm{F}$ & Sig. \\
\hline 1 & Regression & 3303.326 & 3 & 1101.109 & 256.623 & $.000^{\mathrm{b}}$ \\
\hline & Residual & 411.914 & 96 & 4.291 & & \\
\hline & Total & 3715.240 & 99 & & & \\
\hline & ependent $\mathrm{Va}$ & & & & & \\
\hline & redictors: $(\mathrm{C}$ & $x 3, x 1, x 2$ & & & & \\
\hline
\end{tabular}

Sumber: Hasil Olah Data Peneliti

Pada tabel $\mathrm{F}$ di atas nilainya sebesar $256.623>\mathrm{f}$ tabel 2,70 dan jumlah nilai signifikannya adalah 0,000 yang mana $<0,05$. Sehingga peneliti menyimpulkan seluruh variabel independent berpengaruh secara Bersama-sama terhadap variabel dependen $(\mathrm{Y})$.

\section{Simpulan}

Setelah hasil penelitian yang telah peneliti uraikan, maka peneliti dapat menyimpulkan bahwa daya tarik iklan, harga, word of mouth berpengaruh secara positif dan sangat signifikan terhadap minat beli produk Koi Café.

\section{Ucapan Terima Kasih}

Peneliti ingin mengucapkan terima kasih kepada Fakultas Ilmu Komunikasi Universitas Tarumanagara, narasumber, serta semua pihak yang turut membantu peneliti sehingga penelitian ini dapat diselesaikan.

\section{Daftar Pustaka}

Adiba. (2016). Pengaruh Suasana Toko Dan Lokasi Terhadap Minat Beli Konsumen Pada Toko Aurora Shop Samarinda. eJournal Administrasi Bisnis, 4. ISSN: 2355-5408.

Agatha, Maria. (2018). Analisis Pengaruh Harga Terhadap Keputusan Pembelian Batik Barong Gung Tulungagung. Vol 3, No.2.

Gunawan, Fitri, Anggraini., \& Diah, Dharmayanti. (2014). Analisis Pengaruh Iklan Televisi dan Endorser Terhadap Purchase Intention Pond's Men Dengan Brand Awareness Sebagai Variabel Intervening. Jurnal Manajemen Pemasarn Petra Vol.2, No.1, 1-14. 
Hartono, Kefas, Aldi. (2016). Pengaruh Daya Tarik Iklan dan Selebriti Endorser Terhadap Kesadaran Merek dan Dampaknya Terhadap Brand Attitude Mnuman Dalam Kemasan. Skripsi. Universitas Negeri Yogyakarta.

Latief, Rusman., \& Yusiatie, Utud. (2017). Siaran Televisi Non-Drama Kreatif, Produktif, Public Relations, dan Iklan. Jakarta: Kencana.

Veronika. (2016). Pengaruh Iklan Dan Brand Image Terhadap Minat Beli Konsumen, Dengan Brand Image Sebagai Variabel Mediasi. Skripsi. Universitas Sanata Dharma Yogyakarta.

Widodo, Tri. (2015). Pengaruh Labelisasi Halal Dan Harga Terhadap Keputusan Pembelian Konsumen Pada Produk Indomie. Skripsi. Universitas Muhammadiyah Surakarta. 